\title{
Cryogenic Preservation of Isolated Rat Islets of Langerhans: Effect of Cooling and Warming Rates
}

\author{
H. L. Bank, R. F. Davis, and D. Emerson \\ Medical University of South Carolina, Department of Pathology, Charleston, South Carolina, USA
}

\begin{abstract}
Summary. Isolated rat Islets of Langerhans have been frozen to and stored at $-196^{\circ}$. After thawing, these islets were capable of secreting near normal levels of insulin in response to graded glucose challenge. Maximal retention of functional viability as measured by the ability of the islets to secrete insulin in response to a glucose challenge was obtained after freezing islets at a cooling rate of approximately $75^{\circ}$ per minute in the presence of $1.0 \mathrm{~mol} / 1$ dimethyl sulfoxol followed by warming at rates of $>3.5^{\circ}$ minute. The critical freezing parameters include the time and temperature of exposure to dimethyl sulfoxide, the rate of cooling, the temperature of the post-thaw dilution from the freezing medium and the presence of serum in the dilution medium.
\end{abstract}

Key words: Cryobiology, freezing, low-temperature, diabetes, rat, Islets of Langerhans, dimethyl sulfoxide (DMSO), storage, survival, insulin.

Islets of Langerhans can be isolated from several species and maintained in organ culture for moderate periods of time $[1,2,6,11,14]$ but the ability of isolated Islets of Langerhans to secrete insulin in static organ culture diminishes with time. Although storage time can be increased somewhat by keeping the islets at $4^{\circ}$ coupled with intermittent warming [10]. Practical long term preservation will require freezing the islets in a fashion which is not deleterious to either the morphology or physiological response of the islets.

The development of techniques for long-term storage without loss of either morphological integrity or physiological capacity, would simplify many types of long term studies on the biochemical and phy- siological properties of Islets of Langerhans and will be a fundamental step in the development of a practical method for transplantation of islets, between noninbred individuals. Several previous attempts have been made to use low-temperature techniques for adult islet preservation $[8,9,11]$; however, quantitative estimates of survival from these studies were not reported. Here we report the initial results of a survey of the major variables in the cryogenic preservation of rat Islets of Langerhans.

\section{Materials and Methods}

\section{Isolation and Culture}

Islets of Langerhans were isolated from young adult Long-Evans Hooded rats by modification of the method described by Lacy and Kostianovsky [14]. Minced pancreatic tissue was digested with $0.5 \mathrm{mg} / \mathrm{ml}$ Sigma Type 2 collagenase (lot \# 95C6810) dissolved in $20 \mathrm{ml}$ Hank's balanced salt solution, using vigorous agitation in a $37^{\circ}$ water bath. After washing the tissue by centrifugation at 1800 , 800 and $250 \times \mathrm{g}$, the islets were isolated from the surrounding acinar tissue using a Ficoll gradient [19]. All islets were cultured for 16-24 h, before use, in CMRL 1066 tissue culture medium (CMRL) supplemented with $100 \mathrm{mg} / \mathrm{dl}$ Gentamycin and $15 \% \mathrm{v} / \mathrm{v}$ fetal calf serum. The glucose concentration of the culture medium was adjusted to $250 \mathrm{mg} / \mathrm{dl}$ before use. The islets were cultured at $37^{\circ}$ in the presence of $5 \% \mathrm{CO}_{2}$ and $95 \%$ relative humidity.

Islets from a single isolation were pooled, randomized and distributed into sterile Falcon Multiwell Tissue Culture Plates. To minimize the size differentiation between individual islets, 15 randomly selected, morphologically intact islets were placed in each well. Viability of the islets was operationally defined as the ability to secrete insulin in response to a graded challenge of glucose (insulin secretion during one $\mathrm{h}$ in $500 \mathrm{mg} / \mathrm{dl}$ glucose minus nonspecific release in $50 \mathrm{mg} / \mathrm{dl}$ glucose during the subsequent $\mathrm{h}$ ). Insulin carry over was kept at a minimum by washing the islets twice in fresh medium consisting of equal parts CMRL and Dulbecco's Phosphate Buffered Saline (PBS) [7] containing $250 \mathrm{mg} / \mathrm{dl}$ glucose. Then the islets were challenged by exposure to medium composed of equal parts of CMRL and PBS (GIBCO) containing $500 \mathrm{mg} / \mathrm{dl}$ glucose. After one h of incubation at $37^{\circ}$ the supernatant was removed and stored at $-20^{\circ}$ for subsequent analysis. The 
islets were then washed several times in medium consisting of equal parts of CMRL and PBS (final glucose concentration was $50 \mathrm{mg} / \mathrm{dl}$ ). After 15 minutes of equilibration, the islets were again washed in medium containing $50 \mathrm{mg} / \mathrm{dl}$ glucose and allowed to incubate at $37^{\circ}$ for an additional $h$, after which the culture medium was collected as before. The culture medium from both the $500 \mathrm{mg} / \mathrm{dl}$ and the $50 \mathrm{mg} / \mathrm{dl}$ challenges was analyzed for the total amount of insulin present $[20,21]$ with porcine insulin as the standard [21]. All raw data were recorded as $\mu \mathrm{U}$ of insulin secreted per well $/ 0.1 \mathrm{ml}$ medium $/ \mathrm{h}$. Each well of 15 islets was kept as a unit during the entire initial assay, freezing, storage, warming, culturing and reassaying procedures.

\section{Standard Protocol}

Within $1 \mathrm{~h}$ of completion of the glucose challenge, each group of islets was washed in CMRL 1066 (without serum) and transferred, as a group, to $0.1 \mathrm{ml}$ of the CMRL 1066 in degreased, sterile $10 \times$ $75 \mathrm{~mm}$ Pyrex freezing tubes. After placing the freezing tubes in a $+4^{\circ}$ water bath, $0.1 \mathrm{ml}$ of precooled $2.0 \mathrm{~mol} / 1$ dimethyl sulfoxide (DMSO) was added and the contents of the tubes mixed vigorously. Groups of four tubes were attached to an $8^{\prime \prime}$ long Pyrex support rod. After $6 \mathrm{~min}$ at $+4^{\circ}$ the tubes were transferred to a $-4.5^{\circ}$ bath. After $2 \mathrm{~min}$ at $-4.5^{\circ}$ the solutions were artificially induced to freeze, by touching the surface of the medium with a column of ice frozen in the tip of a Pasteur pipette. The heat of crystallization was dissipated during an additional $5 \mathrm{~min}$ holding time at $-4.5^{\circ}$. The tubes were then cooled at $75^{\circ} / \mathrm{min}$ to below $-80^{\circ}$, followed by quenching in liquid nitrogen. All tubes were stored in a liquid nitrogen refrigerator until thawing ( $18 \mathrm{~h}$ to $1 \frac{1}{2}$ years). Samples were warmed at approximately $7.5 \% \mathrm{~min}$. When the temperature of the samples reached the melting point (approximately $-3^{\circ}$ ), $0.2 \mathrm{ml}$ of warm Hank's balanced salt solution (HBSS) containing $10 \%$ fetal calf serum was added and the tubes immediately transferred to a $37^{\circ}$ water bath and the contents mixed vigorously. At $5 \mathrm{~min}$ intervals, additional dilutions were made with HBSS containing $10 \%$ fetal calf serum as follows: $0.2 \mathrm{ml}, 0.4 \mathrm{ml}, 1.0 \mathrm{ml}$ and $1.0 \mathrm{ml}$. The islets were then removed from the freezing tubes and transferred to sterile watch glasses. The freezing tubes were washed with an additional $1.0 \mathrm{ml}$ of HBSS and this solution added to the watch glass. Using this procedure approximately $95 \%$ of the frozen islets were recovered. The islets were then transferred, using a sterile Pasteur pipette, back into the Falcon multi-well test plates and reequilibrated with CMRL medium containing fetal calf serum. In order to allow the islets to recover from the "shock" of the freezing procedure, all islets were incubated at $37^{\circ}$ overnight in the CMRL medium in the presence of $5 \% \mathrm{CO}_{2}$, prior to being tested for their ability to secrete insulin in response to a graded glucose challenge. After this "recovery time" the amount of nonspecific insulin released was substantially lower than when the islets were assayed immediately after thawing.

\section{Variables}

Functional viability was assessed for cooling rates ranging from $0.5^{\circ}$ to $330^{\circ} / \mathrm{min}$, and warming rates of $0.5^{\circ}$ to $1000^{\circ} / \mathrm{min}$. All cooling and warming rates were recorded from a tube containing $0.2 \mathrm{ml}$ of the freezing solution, which was handled in the same fashion as the experimental tubes. Temperature profiles were obtained by measuring the output of a 30 gauge copper-constantan thermocouple wire placed in the freezing solution and the thermocouple output was recorded on a Speedomax Type W multipoint recorder or a Heath Schumberg EU 200 recorder. Details of specific procedures used to obtain cooling and warming rates have been reported elsewhere $[3,5,15]$.
In order to ascertain the optimal time of prefreezing exposure to the cold $\left(4^{\circ}\right)$ cryoprotective agent $(1 \mathrm{~mol} / \mathrm{l} \mathrm{DMSO})$ the islets were exposed for periods of time ranging from 1 to $90 \mathrm{~min}$. At the end of this exposure time, samples were immediately transferred to the $-4.5^{\circ}$ seeding bath and subsequently handled as described in the standard protocol. To ascertain the effects of the freezing medium, the cells were frozen either in PBS (with or without fetal calf serum) or CMRL medium (with or without $10 \%$ fetal calf serum). These samples were frozen according to standard protocol and diluted in the presence of $10 \%$ fetal calf serum at $37^{\circ}$. Other islets were frozen in the presence of CMRL medium and diluted at either $0^{\circ}$ or $37^{\circ}$ in the presence or absence of serum.

\section{Calculations}

Since the level of insulin production of freshly isolated islets from a single animal and randomly distributed between wells often varied substantially from well to well ( 15 or 25 islets per well), gross insulin production of small groups of cultured islets did not always prove to be an adequate measure of viability. Therefore, we attempted to reduce the biological variability by utilizing net insulin production, as measured by insulin release during a $1 \mathrm{~h}$ exposure to a stimulating level of glucose $(500 \mathrm{mg} / \mathrm{dl})$ less the basal level of insulin release under low glucose conditions $(50 \mathrm{mg} / \mathrm{dl})$ during the subsequent $1 \mathrm{~h}$. Determinations of "net glucose sensitive insulin release" were made from each well of islets before freezing and $24 \mathrm{~h}$ after thawing. The results are expressed as the percent of net prefreezing insulin release recovered after freezing. Confidence intervals were determined by "Students" $t$ distribution.

\section{Results}

Net glucose stimulated release of insulin, after cooling at various rates in the presence of $1 \mathrm{~mol} / 1 \mathrm{DMSO}$ are shown in Table 1. Using insulin secretion as a measure of functional viability, insulin secretion increased approximately three-fold as the cooling rates were increased from $1 \% \mathrm{~min}$ to $75 \% \mathrm{~min}$. At faster cooling rates there was a decrease in insulin release. The functional viability of cells frozen at $75^{\circ} \%$ min was highest when the islets were warmed at $>3.5^{\circ} / \mathrm{min}$ (Table 2). For islets frozen with these optimized conditions net insulin released into the culture medium during a glucose challenge was $\sim 75 \%$ of the amount released by the identical islets when challenged prior to freezing. The differences in glucose stimulated insulin release were not statistically different for any of the warming rates $>3.5^{\circ} \mathrm{min}$ $(\mathrm{P}=0.05)$.

Having established the "optimal" cooling velocity at $75 \% \mathrm{~min}$ in the presence of $1 \mathrm{~mol} / 1 \mathrm{DMSO}$, a number of other variables were tested including time of exposure to DMSO and dilution procedures. Maximal functional viability was obtained for isolated islets exposed to $1 \mathrm{~mol} / 1 \mathrm{DMSO}$ at $4^{\circ}$ for $60 \mathrm{~min}$ prior to freezing. Exposure times shorter than $1 \mathrm{~min}$ or longer than $80 \mathrm{~min}$ resulted in poor functional viability after freezing. In response to a glucose chal- 
Table 1. Effect of cooling rate on survival of islets

\begin{tabular}{llllll}
\hline $\begin{array}{l}\text { Cooling rate } \\
\text { in } \% \text { min }\end{array}$ & 1 & 5 & 10 & 75 & 100 \\
\hline $\begin{array}{l}\text { Before freezing } \\
\begin{array}{l}\text { After freezing } \\
\% \text { of prefreezing } \\
\text { value recovered }\end{array}\end{array}$ & $33 \pm 36$ & $58 \pm 24$ & $41 \pm 26$ & $59 \pm 20$ & $52 \pm 20$ \\
\hline
\end{tabular}

Groups of 15 islets were frozen at various rates in the presence of $1 \mathrm{~mol} / 1 \mathrm{DMSO}$. The results are expressed as $\mu \mathrm{U}$ of insulin released in $1 \mathrm{~h}$ into $1.0 \mathrm{ml}$ of culture medium containing $500 \mathrm{mg} / \mathrm{dl}$ glucose minus the basal level of insulin released by the same islets in medium containing $50 \mathrm{mg} / \mathrm{dl}$ measured $24 \mathrm{~h}$ after thawing. Other than cooling rate the islets were frozen using the standard protocol. Each well contained 15 islets and values given represent the mean and standard deviation of five replicates

Table 2. Effect of warming rate on survival of islets

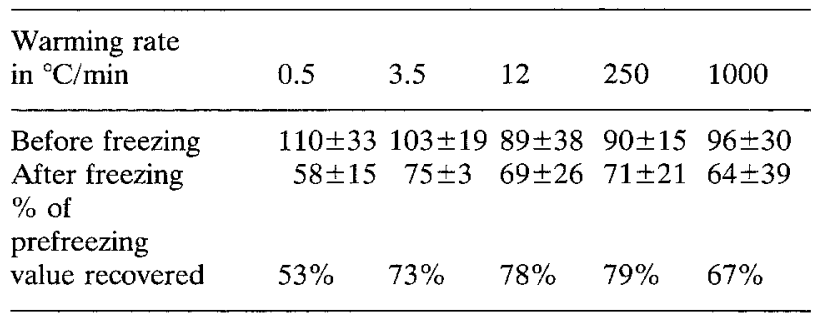

Groups of 15 islets were frozen at $75 \% \mathrm{~min}$ in the presence of $1 \mathrm{~mol} / \mathrm{l} \mathrm{DMSO}$. Values given represent the mean and standard deviation of five replicates. The results are expressed as $\mu \mathrm{U}$ of insulin released in $1 \mathrm{~h}$ into $1.0 \mathrm{ml}$ of culture medium containing $500 \mathrm{mg} / \mathrm{dl}$ glucose minus the basal level of insulin released by the same islets in medium containing $50 \mathrm{mg} / \mathrm{dl}$ by islets $24 \mathrm{~h}$ after thawing. The net insulin production of the identical islets assayed under identical conditions before freezing is also shown. Each sample contained 15 islets and values given represent the mean of four samples. None of the differences were statistically significant

Table 3. Seeded samples in DMSO $(1 \mathrm{~mol} / 1)$

\begin{tabular}{|c|c|c|c|c|c|}
\hline \multirow[t]{3}{*}{ Frozen in: } & CMRL & $127 \pm 33$ & Diluted at: & $0^{\circ} \mathrm{C}$ & $69 \pm 15$ \\
\hline & $\begin{array}{l}\text { CMRL + } \\
\text { Serum }\end{array}$ & $129 \pm 23$ & & $37^{\circ} \mathrm{C}$ & $49 \pm 7$ \\
\hline & $\begin{array}{l}\text { PBS } \\
\text { PBS + } \\
\text { Serum }\end{array}$ & $\begin{array}{l}82 \pm 8 \\
53 \pm 14\end{array}$ & & $\begin{array}{l}37^{\circ} \mathrm{C}+ \\
\text { Serum }\end{array}$ & $235 \pm 37$ \\
\hline
\end{tabular}

The effect of freezing media and dilution procedure on functional survival is shown above. Islets frozen in the presence of CMRL medium consistently showed higher net insulin release than did islets frozen in the presence of phosphate buffered saline, regardless of whether or not the serum was present in the freezing medium. Values represent mean $\pm \operatorname{SD}(n=7)$

lenge, the islets frozen in the presence of CMRL medium released $\sim 1 \frac{1 / 2}{2}$ times more insulin than did islets frozen in phosphate buffered saline. The presence of serum in CMRL had little or no effect on glucose-dependent insulin release provided there was serum present in the dilution medium. When serum was present in the dilution medium, a five-fold increase in total glucose-dependent insulin release, compared to islets diluted at $37^{\circ}$ in the same medium without serum was found (Table 3 ). Long term storage experiments showed no alteration in functional viability for islets stored at $-196^{\circ}$ for up to $1 \frac{1}{2}$ years.

Most islets frozen under conditions which showed relatively high functional viability appeared morphologically intact after thawing. The converse, however, did not hold true. Islets which looked relatively normal upon thawing did not necessarily regain their ability to respond to a glucose challenge [3]. Isolated Islets of Langerhans frozen at $10^{\circ}$ or $75^{\circ} / \mathrm{min}$ and fixed immediately after thawing appeared relatively unaltered when stained with Hematoxylin and Eosin or Aldehyde Fuchsin and examined by light microscopy.

\section{Discussion}

In single celled and multicellular systems which have been quantitatively examined, a maximum "survival" of cells is found to occur at a specific rate of cooling $[3,15,16]$. Alteration of the cooling rate either below or above this optimal rate results in a loss of viability. This indicates that two or more rate dependent factors are responsible for the decrease in viability. At suboptimal cooling velocities, the socalled solution effects result from the progressive conversion of extracellular water into ice. These effects include: cellular dehydration, concentration and precipitation of solutes, $\mathrm{pH}$ changes and "salting out" of membrane proteins. At super-optimal rates of cooling, there is insufficient time for equilibration of the vapor pressure between the hypertonic external medium and the "unfrozen" intracellular water [4]. Therefore, unbound intracellular water can form metastable intracellular ice crystals capable of mechanically disrupting the cells.

Isolated Islets of Langerhans apparently do not act as an integral unit in their response to freezing, rather the freezing rate data indicates that the Beta cells respond as if they were the unit which attempts to remain in osmotic equilibrium. The optimal cooling rate found is comparable to that reported for isolated mammalian fibroblasts frozen under similar conditions $[5,15,16]$. If the islets responded as a whole to the osmotic stress of freezing the optimal cooling rate would be expected to be at least two orders of magnitude lower [16]. When the diameter of the islets was measured, before and at various time intervals after exposure to hypertonic concentrations of DMSO ( 2 to $4 \mathrm{~mol} / \mathrm{l}$ ), no significant change in islet diameter was found, demonstrating that the capsule 
of the islet does not pose as an osmotic barrier to either DMSO or water.

Previous efforts to freeze or store Islets of Langerhans obtained from adult animals, at subphysiological temperatures for extended periods of time have had limited success. Knight [11] reported that isolated rat Islets of Langerhans could be stored at $4^{\circ}$ for up to $48 \mathrm{~h}$, with a loss factor of two in the ability of the islets to secrete insulin in response to the challenge of a high concentration of glucose. Storage of the islets for $72 \mathrm{~h}$ or longer caused a gross inhibition of insulin secretion. A subsequent abstract [12] qualitatively reported "successful" preservation of rat Islets of Langerhans after cooling under conditions comparable to routine tissue culture preservations. Frankel [10] reported that hand-isolated mouse Islets of Langerhans could be stored at $8^{\circ}$ in the presence of $18 \mathrm{mmol} / 1$ glucose for up to five weeks, provided the islets were rewarmed weekly to $37^{\circ}$. Under these conditions glucose-stimulated insulin release was decreased by a factor of $2 / 3$. Ferguson [8] was able to retain some glucose-sensitive insulin release after freezing at $5 \% \mathrm{~min}$ in the presence of DMSO and fetal calf serum and at least $50 \%$ of the islets "survived" based on histological criteria. A subsequent report by Ferguson et al. [9] extended these observations to islets isolated from mice, guinea pigs and humans. They report no histological or functional survival for mouse islets and a highly variable response for human islets frozen at $5 \% \mathrm{~min}$.

Rajotte et al. suspended rat Islets of Langerhans in either 7.5 or $10 \% \mathrm{~V} / \mathrm{V}$ DMSO and frozen at approximately $0.6^{\circ} / \mathrm{min}$ to $-100^{\circ}$ followed by rapid warming in a $37^{\circ}$ water bath [18]. Interpretation of their data is difficult since their control islets did not show glucose sensitive insulin release. Mazur et al. [17] investigated the cryogenic preservation of whole fetal rat pancreases. After removal of the pancreases of 17 day fetuses, the tissue was exposed to warm dimethyl sulfoxide for $1 \mathrm{~h}$ and cooled at rates ranging from 0.2 to $500^{\circ}$ per minute. After thawing at $4^{\circ}$ or $15 \%$ min and gradually diluting with isotonic salt solution, viability was measured by incubating the thawed pancreases in ${ }^{14} \mathrm{C}$ labelled amino acids overnight and then assaying for Trichloroacetic Acid precipitable protein. Isotope incorporation was highest at extremely low rates of cooling (approximately $0.2 \%$ min). It is clear from our study that the optimal cryogenic parameters for the preservation of adult rat Islets of Langerhans differ substantially from that reported for the preservation of fetal rat pancreases $\left(75^{\circ}\right.$ versus $0.2^{\circ}$ ).

In the present study of rat Islets of Langerhans the critical freezing parameters were found to be the type of cryoprotective agent used, the time and tem- perature of exposure to DMSO, the rate of cooling, the temperature at which dilution from the freezing medium occurs and the presence of serum during the dilution procedures. When the freezing parameters are optimized between 75 and $85 \%$ of the islets survived as measured by net glucose sensitive insulin release. A major advantage of such low storage temperatures is that the "functional viability" recovered is essentially independent of storage time.

Acknowledgements. We wish to gratefully acknowledge the capable technical assistance of Ms. Dorothy Noë, Mr. James Scoggin III and Mr. Richard Weiss, without whose help this study would be at a far earlier stage of development. We would like to acknowledge the kind assistance given to us in the development of the isolation procedures and radioimmunoassay by Dr. Lacy and his colleagues Dr. McDaniel, Dr. Nabors and Dr. Gingerrich, and Dr. G. R. Hennigar and Dr. M. Buse for their helpful comments. Research supported in part by the National Institute of Arthritis and Rheumatory Diseases (Grant \# AM-18115) and the American Diabetes Association.

\section{References}

1. Andersson, A., Hellerstrom, C.: Metabolic characteristics of isolated pancreatic islets in tissue culture. Diabetes $\mathbf{2 1}$ (Suppl. 2), 546-554 (1972)

2. Andersson, A., Borg, H., Groth, G., Gunnarsson, R., Hellerstrom, C., Lundgren, G., Westman, J., Ostman, J.: Survival of isolated human Islets of Langerhans maintained in tissue culture. J. Clin. Invest. 57, 1295-1301 (1976)

3. Bank, H., Mazur, P.: Relation between ultrastructure and viability of frozen-thawed Chinese hamster tissue-culture cells. Exp. Cell Res. 71, 441-454 (1972)

4. Bank, H., Mazur, P.: Visualization of freezing damage. J. Cell Biol. 57, 729-742 (1973)

5. Bank, H., Maurer, R. R.: Survival of frozen rabbit embryos. Exp. Cell Res. 89, 188-196 (1974)

6. Buitrago, A., Gylfe, E., Hellman, B., Idahl, L.-A., Johansson, M.: Function of microdissected pancreatic islets cultured in a chemically defined medium. I. Insulin content and release. Diabetologia 11, 535-540 (1975)

7. Dulbecco, R., Vogt, M.: Plaque formation and isolation of pure lines with poliomyelites viruses. J. Exp. Med. 99, 167-182 (1954)

8. Ferguson, J., Allsopp, R. H., Taylor, R. M. R., Johnston, I.D.A.: Isolation and long term preservation of pancreatic islets from mouse, rat and guinea pig. Diabetologia 12, 115-121 (1976)

9. Ferguson, J., Allsopp, R. H., Taylor, R.M. R., Johnston, I. D. A.: Isolation and preservation of islets from mouse, rat, guineapig and human pancreas. Br. J. Surg. 63, 767-773 (1976)

10. Frankel, M. J., Scharp, D. W., Kemp, C. B., Nunnelly, S. B., Ballinger, W. F., Lacy, P. E.: Cryopreservation of pancreatic islets. 9th Congress of European Society for Exptl. Surgery. Eur. Surg. Res. 6 (Suppl. 1), 89 (1974)

11. Knight, M. J., Scharp, D. W., Kemp, C. B., Ballinger, W. F., Lacy, P. E.: Effects of cold storage on the function of isolated pancreatic islets. Cryobiology 10, 89-90 (1973)

12. Knight, M. J., Scharp, D. W., Kemp, C. B., Nunnelly, S. B., Ballinger, W. F., Lacy, P. E.: Cryopreservation of pancreatic islets. 9th Congress of European Society for Exptl. Surgery. Eur. Surg. Res. 6 (Suppl. 1), 89 (1974) 
13. Kostianovsky, M., Lacy, P. E., Grieder, M. H., Still, M. F.: Long term (15 days) incubation of Islets of Langerhans isolated from adult rats and mice. Lab. Invest. 27, 53-61 (1972)

14. Lacy, P. E., Kostianovsky, M.: Method for isolation of intact Islets of Langerhans from the rat pancreas. Diabetes 16, 35-39 (1967)

15. Mazur, P., Farrant, J., Leibo, S. P., Chu, E. H. Y.: Survival of hamster tissue culture cells after freezing and thawing. Cryobiology 6, 1-9 (1969)

16. Mazur, P.: Cryobiology: the freezing of biological systems. Science 168, 939-949 (1970)

17. Mazur, P., Kemp, J. A., Miller, R. H.: Survival of fetal rat pancreases frozen to -78 and $-196^{\circ}$. Proc. Natl. Acad. Sci. USA 73, 4105-4109 (1976)

18. Rajotte, R. V., Stewart, H. L., Voss, W. A. G., Shnitka, T. K., Dossetor, J. B.: Viability studies on frozen-thawed rat Islets of Langerhans. Cryobiology 14, 116-120 (1977)

19. Scharp, D. W., Kemp, C. B., Knight, M. J., Ballinger, W. F., Lacy, P. E.: The use of ficoll in the preparation of viable Islets of Langerhans from the rat pancreas. Transplantation 16, 686-689 (1973)

20. Wright, P. H., Makulu, D. R., Malaisse, W. J., Roberts, N. M., Yu, P. L.: A method for the immunoassay of insulin. Diabetes 17, 537-546 (1968)

21. Wright, P. H., Makulu, D. R., Vichick, D., Sussman, K. E.: Insulin immunoassay by back-titration; Some characteristics of the technic and the insulin precipitant action of alcohol. Diabetes 20, 33-45 (1971)

Received: November 30, 1976,

and in revised form: October 17, 1978

Dr. Harvey Bank

Department of Pathology

Medical University of South Carolina

171 Ashley Ave.

Charleston, SC 29403

USA 